\title{
ECONOMIC LOAD INTERVALS FOR SELECTION OF CABLE SECTIONS FOR AGRICULTURAL PURPOSE
}

\author{
A D Taslimov ${ }^{1}$, M V Melikuziev ${ }^{1}$, A M Najimova ${ }^{3}$, A A Alimov ${ }^{1}$ \\ ${ }^{1}$ Tashkent state technical university, University street №2, Tashkent, 100095, Uzbekistan \\ ${ }^{2}$ Tashkent Institute of Irrigation and Agricultural Mechanization Engineers \\ ${ }^{3}$ Karakalpak State University, 230100, Uzbekistan, Nukus, Ch. Abdirov St. 1
}

\begin{abstract}
The article is devoted to the issues of choosing the optimal cross-section of cables and their scales for the lines of rural electrical networks by the method of economic intervals for various laws of load growth, taking into account the restrictions on long-term permissible current loads and permissible voltage loss, and a comparison of the load boundary obtained on the optimization model with economic intervals is carried out load.
\end{abstract}

\section{Introduction}

Electrical distribution networks for agricultural purposes are characterized by a constant increase in loads. In these conditions, the correct choice of the parameters of power lines and, first of all, the cross-sections of wires of overhead lines and cables of cable lines is of great importance. To select the cross-sections of cable power lines, until now, the economic current density is widely used, which does not meet the condition of the minimum total costs [1-8]. In this regard, it became necessary to determine the economic load intervals for the selection of cable cross-sections and the solution of related problems, taking into account the dynamics of load growth.

In this case, the boundaries of economic intervals for adjacent sections for the case that does not take into account the dynamics of load growth are determined [910]:

$$
S_{\text {гр }}=\sqrt{\frac{\left(E_{\text {н }}+p_{a}\right)\left(K_{i+1}-K_{i}\right) U_{\mathrm{H}}^{2} \gamma F_{i+1} F_{i} 10^{5}}{U_{\Pi}\left(F_{i+1}-F_{i}\right)}}
$$

where $F_{i}$ and $F_{i+1}$ are standard sections; $E_{\mathrm{M}}$ standard efficiency ratio, $p_{a}$ - standard depreciation deduction ratio; $U_{\mathrm{H}}$ - Rated voltage; $K_{i}$ and $K_{i+1}$ values of capital costs; $U_{\mathrm{H}}$ - the cost of compensating for electricity losses.

The boundary values of the economic load intervals, taking into account the dynamics of load changes, are determined:

$$
S_{\Gamma \mathrm{p}}=\sqrt{\frac{\left(E_{\mathrm{H}}+p_{a}\right)\left(K_{i+1}-K_{i}\right) U_{\mathrm{H}}^{2} \gamma F_{i} F_{i+1} 10^{5}}{U_{\Pi}\left(F_{i+1}-F_{i}\right) A}}
$$

where is the coefficient determined by the law of load growth.

To take into account the laws of load growth, the shear coefficient is convenient. In this case, the shift coefficient is determined:

$$
k_{\mathrm{c}}=A^{-\frac{1}{2}}
$$

The shear factor does not depend on the cross-section of the cables and is determined by the factor relative to the load growth (multiplicity of load growth) and the design period.

To study the effect of various laws of load growth on the shear coefficients, appropriate calculations were made. The calculation results are shown in Fig. 1 and 2.

In all possible cases, the shift factor is always greater than one. At the same time, the boundaries of economic load intervals will always be large when choosing cable cross-sections for lines on which the load changes over time. Thus, having determined the boundaries of the economic intervals of the load without taking into account the change in the load over time and using the coefficients of the shift of the boundaries of the economic intervals, it is possible to determine the boundaries of the economic intervals for any laws of growth of the load. 


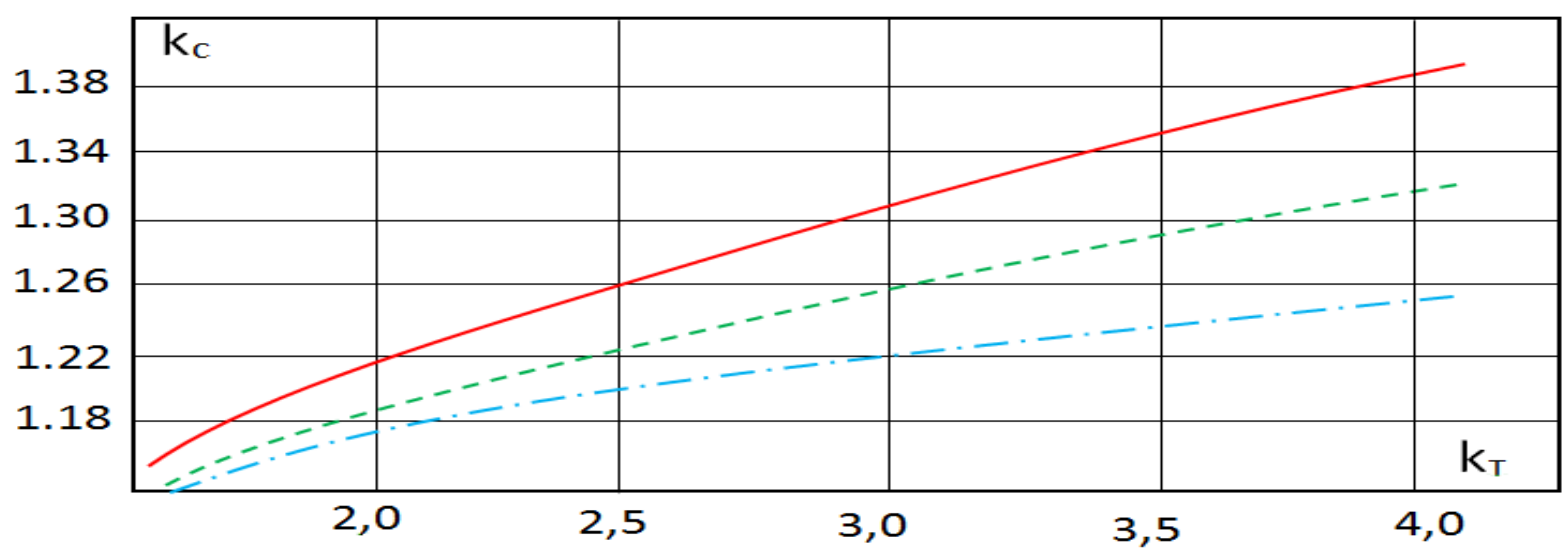

Fig. 1 Dependence of shear coefficients on change

$\boldsymbol{k}_{\mathrm{T}}$ for a) $\boldsymbol{T}=\mathbf{1 5}$ years; $-\boldsymbol{k}_{\mathrm{c}}^{\ni} ;---\boldsymbol{k}_{\mathrm{c}}^{\mathrm{y}} ;-\cdot-\boldsymbol{k}_{\mathrm{c}}^{\mathrm{M}}$;

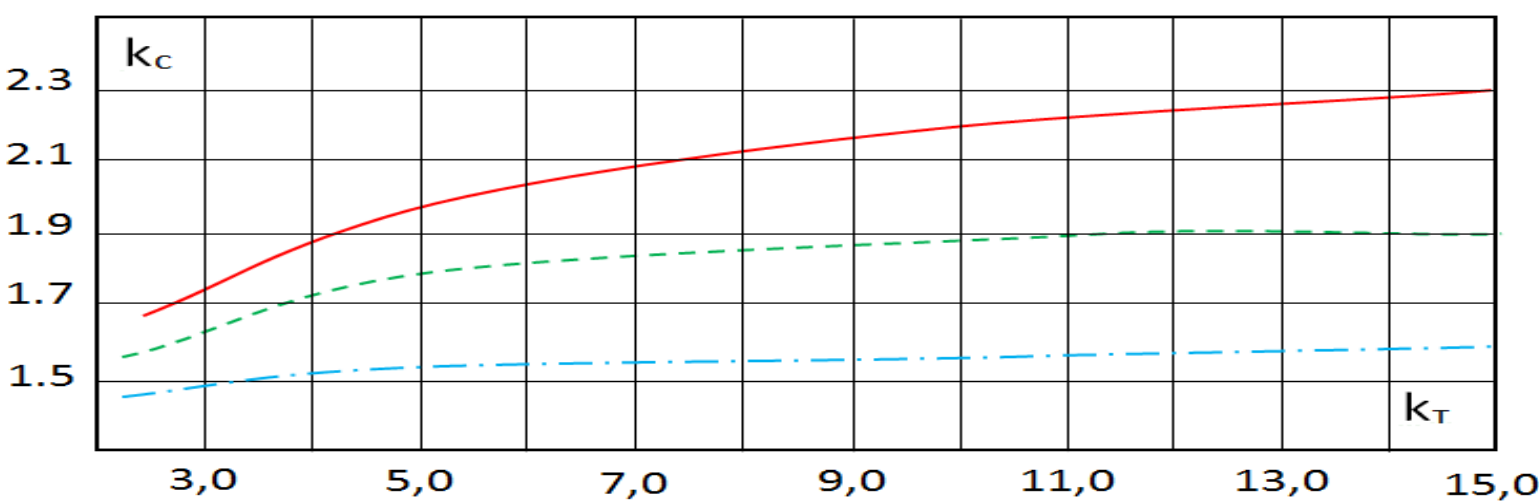

Fig. 2. Dependence of shear coefficients on change

$$
\boldsymbol{k}_{\mathrm{T}} \text { for a) } \boldsymbol{T}=\mathbf{3 0} \text { years } ;-\boldsymbol{k}_{\mathrm{c}}^{\ni} ;---\boldsymbol{k}_{\mathrm{c}}^{\mathrm{4}} ;-\cdot-\boldsymbol{k}_{\mathrm{c}}^{\mathrm{M} \ni} \text {; }
$$

In all possible cases, the shift factor is always greater than one. At the same time, the boundaries of economic load intervals will always be large when choosing cable cross-sections for lines on which the load changes over time. Thus, having determined the boundaries of the economic intervals of the load without taking into account the change in the load over time and using the coefficients of the shift of the boundaries of the economic intervals, it is possible to determine the boundaries of the economic intervals for any laws of growth of the load [11-13].

Comparison of the load boundaries obtained on the optimization model with the economic load intervals showed the following. When the restrictions on long-term permissible current loads and permissible voltage loss are removed, the load boundaries determined according to the proposed program practically coincide with the economic load intervals, the optimization model, determined taking into account the shear coefficient for any duration of the design period (Tables 1-3). Thus, for any settlement period, the boundaries of economic intervals coincide. Based on such a comparison, it can be concluded that the proposed optimization model is correct [14-16].

For calculated periods of 10 and 15 years, the boundaries of economic load intervals determined by the method of economic intervals and by the optimization model, taking into account the limiting conditions, practically coincide (the relative error does not exceed $1 \%$, i.e. the discrepancy is explained by the accuracy of the calculations) [17-22]. With the duration of the calculation period of 20 years, the upper boundaries of the economic load intervals for the cross-section of cable conductors of 50,120,150 and $185 \mathrm{~mm}^{2}$ do not coincide. However, for the rest of the sections, the boundaries of the economic load intervals practically coincide [23-28]. 
The upper limits of economic load intervals, taking into account

\begin{tabular}{|c|c|c|c|c|}
\hline \multirow{2}{*}{ Section, mm2 } & \multicolumn{4}{|c|}{ Calculated period, years } \\
\cline { 2 - 5 } & 10 & 15 & 20 & 30 \\
\hline 16 & 269 & 310 & 363 & 513 \\
\hline 25 & 441 & 507 & 594 & 839 \\
\hline 35 & 569 & 655 & 767 & 1086 \\
\hline 50 & 944 & 1087 & 1272 & 1798 \\
\hline 70 & 1169 & 1346 & 1575 & 2227 \\
\hline 95 & 1456 & 1675 & 1954 & 2772 \\
\hline 120 & 2009 & 2312 & 2707 & 3826 \\
\hline 150 & 2417 & 2782 & 3257 & 4604 \\
\hline 185 & 2856 & 3291 & 3853 & 5445 \\
\hline
\end{tabular}

Table 2

Upper boundaries of economic load intervals according to the model

\begin{tabular}{|c|c|c|c|c|}
\hline \multirow{2}{*}{ Section, mm2 } & \multicolumn{4}{|c|}{ Calculated period, years } \\
\cline { 2 - 5 } & 10 & 15 & 20 & 30 \\
\hline 16 & 268 & 311 & 361 & 525 \\
\hline 25 & 443 & 503 & 594 & 831 \\
\hline 35 & 567 & 658 & 765 & 1051 \\
\hline 50 & 948 & 1095 & 1274 & 1795 \\
\hline 70 & 1170 & 1346 & 1572 & 2232 \\
\hline 95 & 1453 & 1672 & 1954 & 2801 \\
\hline 120 & 2009 & 2315 & 2718 & 3852 \\
\hline 150 & - & 2781 & 3250 & 4596 \\
\hline 185 & - & - & 3865 & 5472 \\
\hline
\end{tabular}

Table 3

Economic load intervals according to the optimization model taking into account the limiting conditions

\begin{tabular}{|c|c|c|c|c|}
\hline \multirow{2}{*}{ Section, mm2 } & \multicolumn{4}{|c|}{ Calculated period, years } \\
\cline { 2 - 5 } & 10 & 15 & 20 & 30 \\
\hline 16 & 268 & 311 & 361 & 394 \\
\hline 25 & 443 & 503 & 595 & 613 \\
\hline 35 & 567 & 651 & 765 & 832 \\
\hline 50 & 948 & 1095 & 1189 & 1269 \\
\hline 70 & 1175 & 1346 & 1572 & 1751 \\
\hline 95 & 1453 & 1672 & 1954 & 2145 \\
\hline 120 & - & 2308 & 2570 & 5122 \\
\hline 150 & - & 2781 & 3101 & 6347 \\
\hline 185 & - & - & 3674 & 7310 \\
\hline
\end{tabular}

Thus, the boundaries of the loads determined by the proposed optimization model without taking into account the influence of the limiting conditions fully correspond to the boundaries of the economic intervals of the load, determined taking into account the shear coefficient, subject to the conditions of comparability. To select the cable sections of the lines, the relationships were established between the boundaries of the economic load intervals, the values of the load intervals themselves and the value of the total costs at the boundaries of the economic load intervals. The influence of the nature and dynamics of changes in the load on the boundaries of economic intervals is investigated and the shift coefficient is proposed.

\section{References}

1. Calculation of power transmission lines for agricultural purposes: a textbook for students p. $\mathrm{x}$. universities // G.I. Yanukovich 2nd ed., add. - Minsk: BGATU, 2004 .- 105p.

2. Zuev E.N., Efentiev S.N. The tasks of choosing economically feasible sections of wires and cables: textbook. allowance. M .: MEI, 2005 .- 88p.

3. Taslimov A.D., Shaimatov B.Kh., Kholmurodov M.B. Unification of cable cross-sections for distribution electrical networks taking into account the growth of loads. International scientific and technical conference 
"Modern techniques and technologies of the mining and metallurgical industry and ways of their development" / Navoi, 2013. - pp. 147-149.

4. Saidkhodjaev A G, Najimova A M and Bijanov A K 2019 Method for determining the maximum load of consumers in city power supply systems E3S Web Conf 139 doi:10.1051/e3sconf/201913901078.

5. Taslimov A D, Rakhmonov I U 2019 Optimization of complex parameters of urban distribution electric networks Journal of Physics: Conference Series 1399 doi:10.1088/1742-6596/1399/5/055046

6. Rakhmonov I U, Niyozov N N 2019 Optimization setting of steel-smelting industry in the issue of alloy steels E3S Web Conf 139 doi:10.1051/e3sconf/201913901077

7. Rakhmonov I U, Reymov K M and Shayumova Z M 2019 The role information in power management tasks. E3S Web Conf 139 doi:10.1051/e3sconf/201913901080

8. Rakhmonov I U, Tovbaev A N, Nematov L A and Alibekova T Sh 2020 Development of forecasted values of specific norms for the issues of produced products in industrial enterprises Journal of Physics: Conference Series 1515 doi:10.1088/1742-6596/1515/2/022050

9. Rakhmonov I U, Nematov L A, Niyozov N N, Reymov K M and Yuldoshev T M 2020 Power consumption management from the positions of the general system theory Journal of Physics: Conference Series 1515 doi:10.1088/1742-6596/1515/2/022054

10. Rakhmonov I U, Reymov K M, Najimova A M, Uzakov B T and Seytmuratov BT 2019 Analysis and calculation of optimum parameters of electric arc furnace Journal of Physics: Conference Series 1399 doi:10.1088/1742-6596/1399/5/055048

11. Taslimov A D, Berdishev A S, Melikuzuev M V and Rakhimov F M 2019 Method of selecting parameters of cable lines distributive networks $10 \mathrm{kv}$ in uncertainty $\begin{array}{llll}\text { conditions } & \text { E3S } & \text { Web } & \text { Conf }\end{array}$ doi:10.1051/e3sconf/201913901082

12. Taslimov A D, Berdishev A S, Melikuziyev M V and Rakhimov F M 2019 Method of choosing the unification of cable sections of electric network cables under conditions of load development uncertainty E3S Web Conf 139 doi:10.1051/e3sconf/201913901081

13. Rakhmonov, I.U., Berdishev, A.A., Khusanov, B.M., Khaliknazarov, U., Utegenov, U. (2020) General characteristics of networks and features of electricity consumers in rural areas Journal of IOP: Conference Series. MIP: Engineering-2020. 883 (2020) 012104 doi:10.1088/1757-899X/883/1/012104

14. Karimov R.Ch., Shamsiyev K., and others. IOP Conf. Series: Materials Science and Engineering, 883(1), 012142, (2020). doi:10.1088/1757-899X/883/1/012142

15. Karimov R.Ch., Shamsiyeva N. and others. IOP Conf. Series: Materials Science and Engineering, 883(1), 012120, (2020). doi:10.1088/1757-899X/883/1/012120

16. E.G.Usmanov, A.N.Rasulov, M.K.Bobojanov, R.Ch.Karimov. E3S Web of Conferences 139, 01079 (2019), doi.org/10.1051/e3sconf/201913901079

17. Bobojanov M.K., Rasulov A.N., Karimov R.Ch., Sattarov H.A. Bulletin Descendants of Mohammed AlKhwarizmi (ISSN: 2181-9211), Tashkent, 3(5), - PP.106109, (2018).
18. Burievich, T.J. The questions of the dynamics of drilling bit on the surface of well bottom// Arch. Min. Sci. -Poland. - Vol. 61 (2016). - №2. - P. 279-287. DOI 10.1515/amsc-2016-0020.

19. Toshniyozov, L.G., Toshov, J.B. Theoretical and experimental research into process of packing in drilling// Mining Informational and Analytical Bulletin Volume 2019, Issue 11, 2019, Pages 139-151. DOI: 10.25018/0236-1493-2019-11-0-139-151.

20. Azamatovich, A.N., Amrillo, M.B, Burievich, T.J., Umarxanoxich, J.R., Shavkatovich, Z.A. A complex of methods for analyzing the working fluid of a hydrostatic power plant for hydraulic mining machines / International Journal of Advanced Science and Technology. Volume 29, Issue 5 Special Issue, 28 March 2020, Pages 852-855

21. Hoshimov, F.A., Bakhadirov, I.I., Erejepov, M., Djumamuratov, B. (2019) Development of method for normalizing electricity consumption E3S Web Conf 139 doi:10.1051/e3sconf/201913901074

22. G.R.Rafikova, M.R.Ruzinazarov, S.K.Makhmutkhonov. E3S Web of Conferences, 139, 01075 ,

https://doi.org/10.1051/e3sconf/201913901075

(2019),

23. Allayev, K.R., Fedorenko, G.M.,Postnikov, V.I.,Ostapchuk, L.B. Asynchronous generators as power system's natural dampers. 43rd International Conference on Large High Voltage Electric Systems 2010, CIGRE 20102010, 9p43rd International Conference on Large High Voltage Electric Systems 2010, CIGRE 2010; Paris; France; 22 August 2010.

24.Fazylov, Kh.F.,Allaev, K.R. Analysis of the operation of an electrical system during simultaneous operation of synchronous and asynchronous generators. Power engineering New York Volume 18, Issue 3, 1980, Pages 81-88.

25.Fazylov, Kh.F.,Allaev, K.R. Asynchronous turbogenerators with stator excitation and the prospects for their utilization. Power engineering New York Volume 23, Issue 2, 1985, Pages 7-13.

26.Fazylov, Kh.F.,Allaev, K.R. Calculation and experimental analysis of conditions of electrical power systems containing induction generators Power Engineering New York Volume 27, Issue 6, 1989, Pages 27-34.

27.Allaev K., Makhmudov T. Research of small oscillations of electrical power systems using the technology of embedding systems. Electrical Engineering, 2020; Issue 1: 309-319.DOI 10.1007/s00202-019-00876-9

28.Allaev K., Makhmudov T. Prospects of diversification and ensuring energy safety of Uzbekistan. E3S Web Conf., Volume 139, 2019, Rudenko International Conference "Methodological problems in reliability study of large energy systems" (RSES 2019).https://doi.org/10.1051/e3sconf/201913901002 